\title{
Comparison of Two Extraction Methods for Spirogyra Extracellular Polymeric Substances
}

\author{
Shui-Ping Chang, Hwey-Lin Sheu, Yi-Chao Lee*, Chih-Sheng Lee \\ Department of Environmental Engineering \\ Kun Shan University \\ Tainan City, Taiwan (R.O.C.) \\ spchang@mail.ksu.edu.tw, sheu@mail.ksu.edu.tw, lyc007@mail.ksu.edu.tw*, cslee@mail.ksu.edu.tw
}

\begin{abstract}
Microbial extracellular polymeric substances (EPS) have been considered as important renewable resources and technologies. Lately many studies are looking for valuable EPS as well as algae with production potentials and corresponding extraction methods. Spirogyra spp. is a genus of large filamentous green algae commonly found in freshwater areas? Under natural circumstances, Spirogyra spp. excretes large amounts of EPS and forms a mucilage layer. This study used two algal EPS extraction methods such as ultrasonication and heating to compare the extraction yields of EPS and the levels of its primary components of polysaccharides and proteins. The results indicated that the extraction yields of EPS using heating and ultrasonication are $29.4 \mathrm{mg}$ EPS/g-fresh algae and $15.8 \mathrm{mg}$ EPS/g-fresh algae, respectively. The ratio of polysaccharides to proteins in EPS is around 1.85 to 2.16, which is not a significant difference between the two extraction methods. In other words, the level of polysaccharides is always higher than the level of proteins in EPS extraction with both two methods. This study exhibited the developmental potential of Spirogyra and the industrial application of EPS by exploring extraction methods of Spirogyra and the features of EPS.
\end{abstract}

Keywords-Spirogyra; extracellular polymeric substance (EPS); polysaccharide; protein

\section{INTRODUCTION}

EPS are metabolites accumulated on the surface of microcells. They not only stabilize the structure of plasma membranes but also protect cells against external harsh environments. EPS are high molecular isomeric polymers, which primarily consist of polysaccharides, proteins, nucleic acids and fats [1]. Therefore, they can be transformed and become the source of carbon and energy during starvation [2].

EPS can be found in bacteria [3], cyanobacteria [4], marine microorganisms and fungi $[5,6]$. Spirogyra spp. is a genus of large filamentous green algae commonly found in freshwater areas all over the world? The cell surface of Spirogyra spp. can excrete large amounts of EPS and the $\mathrm{n}$ form a unique mucilage layer. However, the extraction methods of Spirogyra spp. and the features of EPS were not explored.

The application of microbial EPS in the industry has been valued highly $[7,8]$. In the food industry, EPS can be used as a thickener and gel to improve food quality and texture. In medicine, EPS is used as a hydrophilic matrix to control the release of medicines, or can be used in the development of

"The work was supported by the conceptual development of science, research, and innovation for the year 2015 allocated to VSB-TUO by Ministry of Education, Youth and Sports of Czech Republic". bacterial vaccines and increase non-specific immunity [9]. In addition, EPS also improves the process of heavy metal- and radio nuclides-contaminated water by enhancing the water retention capacity of the soil [10]. The demands for natural polymers in various industrial applications have increased lately, and therefore, novel algae have been used to synthesize high-value products, such as products of high aggregated value such as pigments, osmoprotectant, metabolites, fatty acids and proteins, may also be exploited for EPS as biosurfactants and/or bio-emulsifiers $[11,12]$.

This study compared the EPS extraction yield of the large freshwater algae Spirogyra spp. and the levels of its primary major components of polysaccharides and proteins with two different physical extraction methods of ultrasonication and heating. We expect to establish an EPS extraction-based biotechnology from Spirogyra spp. and explore its potential in industrial development.

\section{MATERIALS AND METHODS}

\section{A. Algae}

The algae that were used in this study was the large filamentous superior green algae Spirogyra fluviatilis, which grows naturally in freshwater areas in Taiwan. The algae were washed twice with tap water, placed in a strainer at room temperature for $2 \mathrm{hrs}$ to naturally drain the water, and then used for EPS extraction.

\section{B. EPS Extraction Methods}

In extraction methods, cationic exchange resin (CER) is not suitable for EPS extraction from large filamentous algae $[13,14]$, Therefore we used two physical methods, heating, and Ultrasonication, to extract EPS.

(1) Ultrasonication: $50 \mathrm{~g}$ fresh algae $+0.05 \%(\mathrm{w} / \mathrm{w}) \mathrm{NaCl}$ solution to $100 \mathrm{ml}$, was sonicated at $120 \mathrm{~W}$ for $10 \mathrm{~min}$.

(2) Heating: $50 \mathrm{~g}$ fresh algae $+0.05 \%(\mathrm{w} / \mathrm{w}) \mathrm{NaCl}$ solution to $100 \mathrm{ml}$, was heated at $80^{\circ} \mathrm{C}$ for $10 \mathrm{~min}$.

The treated suspension was centrifuged $(10,000 \times \mathrm{g})$ for 10 min with the suspension being collected. All supernatants were diluted by Mili-Q water to at the same level and then filtrate using $0.45 \mu \mathrm{m}$ cellulose nitrate membrane filter with filtrate collected.

The flowchart of extraction procedures is shown in Fig. 1. 


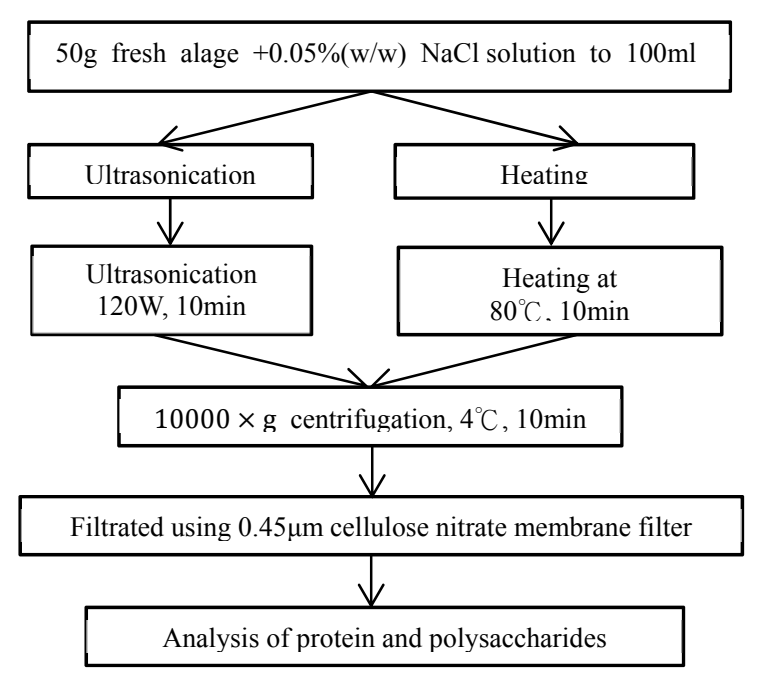

Fig. 1. Procedure for 2 extraction process of S. fluviatilis EPS.

\section{Analysis Method}

All chemicals used in this work were of analytical grade. Polysaccharide content was determined by the phenol-sulfuric acid [15] using glucose as a standard. Protein content was determined according to Bradford (1976) [16] with bovine serum albumin BSA, Sigma A2153 100mg/ml) [17]. The total EPS content was measured as the sum of these two substances.

\section{RESUlts AND DISCUSSION}

A. Comparison of Different Physical Extraction Methods for Assessing the Levels of Proteins and Polysaccharides of Spirogyra EPS

The protein levels from different physical extraction methods were measured using common testing kits. The results were shown in Table I. and Fig. 2 . The results revealed that the protein level with the heating method was significantly higher than the protein level with the ultrasonication method. Similarly, the polysaccharides levels from different physical extraction methods were measured using a phenol-sulfulric kit and are shown in Table II and Fig. 3. The data reflect the average results from 6 repeated measurements, which showed that the average polysaccharides weight of EPS extraction with the heating method was $17.9 \mathrm{mg}$-polysaccharides/g-fresh algae, $\mathrm{w} / \mathrm{w}$, but the average weight of polysaccharides with ultrasonication was only $10.8 \mathrm{mg}$-polysaccharides/g-fresh algae, w/w. Based on the aforementioned data, we can conclude that heating also has a greater extraction yield of polysaccharides than ultrasonication.

TABLE I. COMPARISON OF PROTEIN LEVEL FOR USING HEATING AND ULTRASONICATION EPS EXTRACTION METHOD

\begin{tabular}{|c|c|c|}
\hline Extraction method & Heating & Ultrasonication \\
\hline Sample No. & 9.4 & 6.2 \\
\hline 1 & 4.2 & 3.1 \\
\hline 2 & 11.1 & 6.5 \\
\hline 3 & 13.3 & 6.9 \\
\hline 4 & 9.9 & 3.5 \\
\hline 5 & 10.7 & 4.0 \\
\hline 6 & 9.7 & 5.0 \\
\hline Mean & \multicolumn{2}{|c|}{ Unit $:$ mg-protein /g-fresh alage weight } \\
\hline & \multicolumn{2}{c|}{}
\end{tabular}

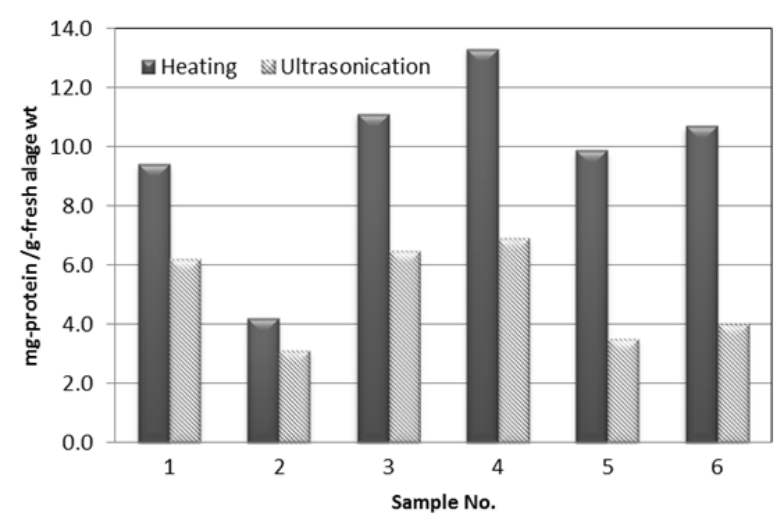

Fig. 2. Protein level for heating and ultrasonication EPS extraction method.

TABLE II. COMPARISON OF PROTEIN LEVEL FOR USING HEATING AND ULTRASONICATION EPS EXTRACTION METHOD

\begin{tabular}{|c|c|c|}
\hline Sample No. & Heating & Ultrasonication \\
\hline 1 & 15.3 & 10.5 \\
\hline 2 & 14.4 & 8.9 \\
\hline 3 & 17.6 & 11.8 \\
\hline 4 & 21.1 & 12.3 \\
\hline 5 & 18.3 & 9.9 \\
\hline 6 & 20.6 & 11.3 \\
\hline Mean & 17.9 & 10.8 \\
\hline & \multicolumn{2}{|c|}{ Unit $:$ mg- polysaccharides /g-fresh alage weight } \\
\hline
\end{tabular}

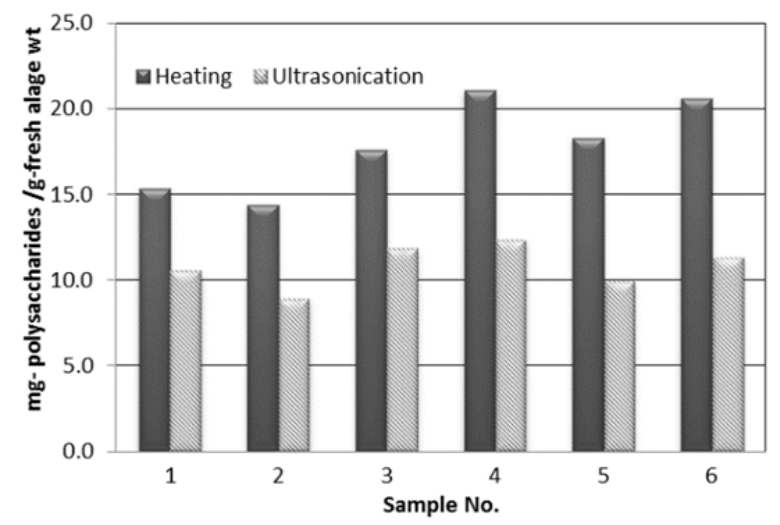

Fig. 3. Polysaccharides level for heating and ultrasonication EPS extraction method.

\section{B. Comparison of Heating and Ultrasonication Extraction Methods for the Extraction Yield of Spirogyra EPS}

The results are shown in Table III and Fig. 4. The results demonstrated that heating has a greater extraction yield of EPS than ultrasonication. Although heating has a greater extraction yield of EPS, the results were consistent with the results published by Sun et al. [13], which compared different extraction methods for Bacillus megaterium EPS. Ultrasonication generates transient cavitations and acoustic streaming in the liquid and lowers the coulomb and van der Waals forces between EPS and cells [14, 18]. 
TABLE III. COMPARISON OF EPS FOR USING HEATING AND ULTRASONICATION EPS EXTRACTION METHOD

\begin{tabular}{|c|c|c|}
\hline Extraction method & Heating & Ultrasonication \\
\hline 1 & & 16.7 \\
\hline 2 & 24.7 & 12 \\
\hline 3 & 18.6 & 18.3 \\
\hline 4 & 28.7 & 19.2 \\
\hline 5 & 34.4 & 13.4 \\
\hline 6 & 28.2 & 15.3 \\
\hline Mean & 31.3 & 15.8 \\
\hline & 27.6 & Unit $:$ mg- EPS $/ \mathrm{g}$-fresh alage weight \\
\hline
\end{tabular}

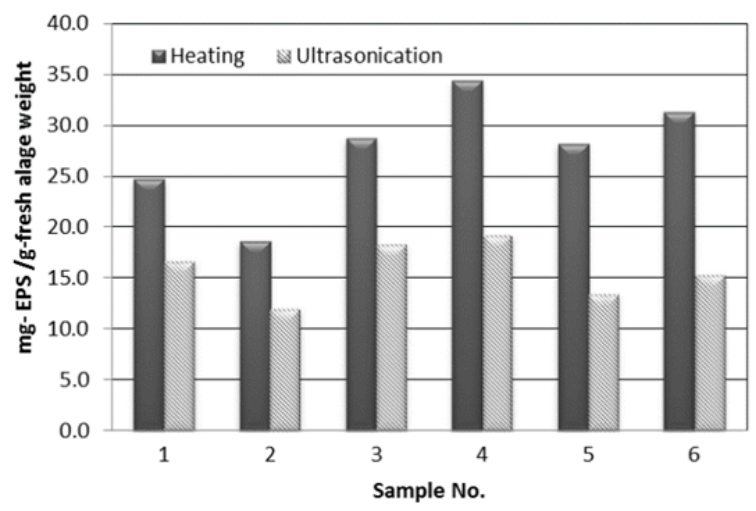

Fig. 4. EPS for heating and ultrasonication EPS extraction method

Different extraction methods have different extraction yields of EPS. In this study, even though heating has significantly greater extraction yields of EPS than ultrasonication, the power of ultrasonication may also impact the extraction yield of EPS. For example, excessive power may result in algae cell fragmentation, and intracellular components may thus compromise the quantity of the EPS. This study also discovered that the power used in ultrasonication should be varied depending on the types of the algae.

This study further compared the primary components of EPS (polysaccharides and proteins) with different extraction methods. The results showed that although different extraction methods can lead to different extraction yields of EPS, the ratio of polysaccharides to proteins in EPS did not reach significant differences. It was between 1.85-2.16. In other words, different extraction methods may influence the extraction yields of EPS, but they did not have a significant impact on the ratio of the primary components.

\section{CONCLUSION}

To compare the extraction yields of EPS from large $S$. fluviatilis and the changes in its primary major components of polysaccharides and proteins with different physical extraction methods, the study results showed that:

1. Heating has a greater extraction yield of EPS than ultrasonication method.

2. The ratio of polysaccharides to proteins in EPS is around 1.05 to 1.38 , which is not a significant difference with the two extraction methods. In other words, the level of polysaccharides is always higher than the level of proteins in EPS extraction with the two methods.

Genus of Spirogyra is a biomaterial with great potentials. In its natural habitat, Spirogyra spp. can produce large amounts of EPS, therefore it has great potential in EPS extraction. These preliminary study results helped us understand the extraction methods of EPS applicable to large algae, and the influences on its primary components. We conclude that ultrasonication and heating are both suitable for EPS extraction methods for large algae.

\section{REFERENCES}

[1] B.S. McSwain, R.L. Irvine, M. Hausner, and P.A. Wilderer, "Composition and distribution of extracellular polymeric substances in aerobic flocs and granular sludge," Appl. Environ. Microbiol. vol. 71, pp. 1051-1057, 2004.

[2] L. Gao, X.L. Pan, D.Y. Zhang, S.Y. Mu, D.J. Lee, and U. Halik, "Extracellular polymeric substances buffer against the biocidal effect of $\mathrm{H} 2 \mathrm{O} 2$ on the bloom-forming cyanobacterium Microcystis aeruginosa," Water Res. vol. 69, pp. 51-58, 2015.

[3] F. Freitas, V.D. Alves, J. Pais, N. Costa, C. Oliveira, and L. Mafra, "Characterization of an extracellular polysaccharide produced by a Pseudomonas strain grown on glycerol,” Bioresource Technol. vol. 100, pp. 859-865, 2009.

[4] Z. Chi, C.D. Su, and W.D. Lu, "A new exopolysaccharide produced by marine Cyanothece sp. 113.," Bioresource Technol. vol. 98, pp. 13291332, 2007.

[5] M. Lundkvist, U. Gangelhof, J. Lunding, and M.R. Flindt, "Production and fate of extracellular polymeric substances produced by benthic diatoms and bacteria: A laboratory study," Estuar. Coast. Shelf Sci. vol. 75, no. 3, pp. 337-346, 2007.

[6] R. Jain, S. Raghukumar, R. Tharanathan, and N.B. Bhosle, "Extracellular polysaccharide production by Thraustochytrid Protists," Marine Biotechnol. vol. 7, pp. 184-192, 2005.

[7] A.S. Kumar, K. Mody, and B. Jha, "Bacterial exopolysaccharides-a perception,” J. Basic Microbiol. vol. 47, pp. 103-117, 2007.

[8] M. Avinash, K. Kumari, and J. Bhavanath, "Characterization of extracellular polymeric substances produced by micro-algae Dunaliella salina," Carbohyd. Polym. vol. 83, pp. 852-857, 2011.

[9] B.S. Subramanian, S. Yan, R.D. Tyagi, and R.Y. Surampalli, "Extracellular polymeric substances (EPS) producing bacterial strains of municipal wastewater sludge: Isolation, molecular identification, EPS characterization and performance for sludge settling and dewatering", Water Res. vol. 44, pp. 2253-2266, 2011.

[10] X. Zou, M. Sun, and X. Guo, "Quantitative response of cell growth and polysaccharide biosynthesis by the medicinal mushroom Phellinus linteus to $\mathrm{NaCl}$ in the medium," World J. Microbiol. Biotechnol. vol. 22, pp. 1129-1133, 2006.

[11] A. Mishra, and B. Jha, "Isolation and characterization of extracellular polymeric substances from micro-algae Dunaliella salina under salt stress," Bioresource Technol. vol. 100, pp. 3382-3386, 2006.

[12] S.K. Satpute, I.M. Banat, P.K. Dhakephalkar, A.G. Banpurkar and B.A. Chopade, "Biosurfactants, bioemulsifiers and exopolysaccharides from marine microorganisms," Biotechnol. Adv. vol. 28, pp. 436-450, 2010.

[13] M. Sun, W.W. Li, H.Q. Yu, and H. Harada, "A novel integrated approach to quantitatively evaluate the efficiency of extracellular polymeric substances (EPS) extraction process," Appl. Microbiol. Biotechnol, vol. 96, pp. 1577-1585, 2012.

[14] Z.M. Wang, Y.C. Cheung, P.H. Leung, J.Y. Wu, "Ultrasonic treatment for improved solution properties of a high-molecular weight exopolysaccharide produced by a medicinal fungus," Bioresource Technol. vol. 101, no. 14, pp. 5517-5522, 2010.

[15] H. Xiaomeng, W. Zhiwei, Z. Chaowei, and Z. Wu, "Effect of ultrasonic power density on extracting loosely bound and tightly bound 
extracellular polymeric substances," Desalinat. vol. 329, no. 15, pp. 3540, 2013.

[16] M. M. Bradford, "A rapid and sensitive method for the quantitation of microgram quantities of protein utilizing the principle of protein-dye binding," Anal Biochem vol. 72, pp. 248-254, 1976.
[17] M. Dubois, K.A. Gilles, J.K. Hamilton, P.A. Rebers, and F. Smith, "Colorimetric method for determination of sugars and related substances,” Anal. Chem. vol. 28, no. 3, pp. 350-356, 1956.

[18] B. Frolund, R. Palmgren, K. Keiding, and P.H. Nielsen, "Extraction of extracellular polymers from activated sludge using a cation exchange resin," Water Res. vol. 30, no. 8, pp. 1749-1758, 1996. 